\title{
Tratado rápido de filosofía y otros poemas
}

\section{Fast Treaty of philosophy and other poems Da filosofia Tratado Rápido e outros poemas}

\author{
Bartolomé Nieto Munuera \\ 1Poeta, licenciado en Filosofía y Letras por la Universidad de Granada y formador experto por la \\ Universidad Complutense de Madrid. \\ Cómo citar este poema en edición digital: Nieto Munuera, B. (2014) Tratado rápido de filosofía y otros poemas. Cultura de los \\ Cuidados (Edición digital) 18, 39. Disponible en: http://dx.doi.org/10.7184/cuid.2014.39.04> \\ Correo electrónico: Carmen Pérez Gutiérrez<carmenpg9@gmail.com>
}

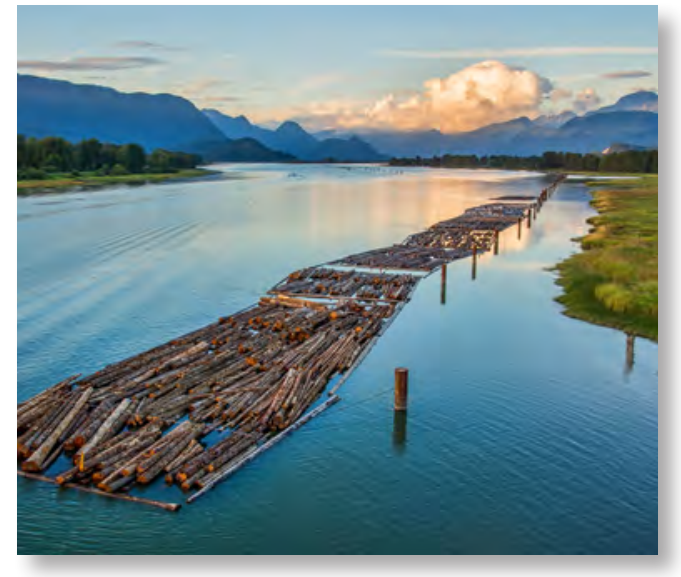

\section{ABSTRACT}

We present in "Fast Treaty of philosophy and Other Poems", four poems selected from three poetry books written by Bartolomé Nieto Munuera, tireless crosser lyrics and feelings seas subject to tides, algae and mosses: Ribera de la entropía, La estirpe del aire, y Noches de Quart Hadasht. Although he died prematurely, this great poet had time to give us a strong and consistent work where saturated interpretations abound intelligence and aesthetic whose serenity rocks in critical thinking dialectically verses giving us an almost unfathomable depth. Nieto interpreta a realidade como a vida e pensa deixando um perfume delicado translúcido segue lentamente o ritmo da pura beleza deste poeta culto e intuitiv.Nieto interprets reality as he lives and thinks segregating a delicate perfume that emerges slowly in time to the unredeemed neatness of this poet cultivated and intuitive.

Keywords: poetry, anthro-poetic phenomenology

\section{RESUMO}

Apresentamos "filosofia Tratado rápido e Outros Poemas", quatro poemas selecionados três poemas escritos por Bartolomé Nieto $\mathrm{Mu}-$ nuera, nadador incansável Mares letras e sentimentos sujeitas a marés, algas e musgos: Banco da entropia, O ar linhagem Noites e Hadasht Quart. Apesar de sua morte prematura, este grande poeta tem tempo de sobra para dar-nos um trabalho forte e consistente, onde há muitas interpretações da inteligência e da estética, cuja serenidade é balanceada na dialética e os versos críticvo pensamento e nos dá uma profundidade quase insondável. Nieto interpreta a realidade como a vida e pensa deixando um perfume delicado translúcido segue lentamente o ritmo da pura beleza deste poeta culto e intuitivo.

Palavras -chave: poesia, fenomenologia antro-poética.

\section{RESUMEN}

Se presentan en "Tratado rápido de filosofía y otros poemas", cuatro poemas seleccionados de tres poemarios escritos por Bar- 
tolomé Nieto Munuera, surcador incansable de mares de letras y sentimientos sujetos a mareas, algas y musgos: Ribera de la entropía, La estirpe del aire, y Noches de Quart Hadasht. A pesar de su prematura muerte, a este gran poeta le ha sobrado tiempo para regalarnos una obra intensa y coherente donde abundan interpretaciones saturadas de

\section{Tratado rápido de filosofía}

"Vivir para mí es extender la muerte"

(Al-Mutanabbi)

El tiempo blando

El amor caníbal

La belleza trágica

Lastimosas palabras

Sueño amagado

El arte

Cadáver místico

Entre carne

Y sentimiento

Generalmente

Me caigo del deseo.

Bartolomé Nieto Munuera (2006) Ribera de la Entropía. Editorial Alhulia, Salobreña: p-68 inteligencia y una estética cuya serenidad se mece dialécticamente en el pensamiento crítico regalándonos versos de una profundidad casi insondable. Nieto interpreta la realidad como la vive y la piensa dejando translucir un perfume delicado que se desprende lentamente al son de la pulcritud irredenta de este hermeneuta culto e intuitivo.

\section{La antesala}

Para el lento viaje de las algas que ha de llevarme a vuestra paz de limo tengo preparados los estigmas, el sueño en custodia y la incólume acidez in techo.

He doblado bien mi ropa tengo dispuesto el aparejo limpios los zapatos bajo la cama las gafas rectas, mi lisa vocación de muerto en el armario Me acompañan los incendios del agua clavados en la nuca y la hiel vociferante del neón en el vestíbulo abyecto.

Desde esta laguna oscura atisbo las palabras que han dejado de ser inocentes la luz sofista de los bosques el hervidero gregario de los ángeles caídos Me acompañan los lamentos lejanos de un parto de arañas y escupo la memoria todavía insolente de una playa desnuda Montado en los ojos de la noche camino, pertrechado de olvidos, a ese tálamo ruin que nos espera con el metal que atruena en los versículos en la implacable pretensión del aire.

Bartolomé Nieto Munuera (2014) La Estirpe del Aire. Editorial Alhulia, Salobreña: p-32. 


\section{Suicidio azul}

(El Portús)

De pie

En el acantilado

(cortar)

Las amarras

Bartolomé Nieto Munuera (2014) Noches de Quart Hadasht. Huerga \& fierro/ Colección el Diván, Madrid: p-43

\section{Espartaria}

Para beber de nuevo la luz escondida De los muelles

Hemos vuelto de otra noche inmortal En inocentes sintagmas de futuro

Con las jarcias roncas y las manos De yesca

Al útero eterno de un cielo impostor Donde cuelgan del aire Las palabras nuevas

Duerme nuestra patria de albardín En finas jeringuillas de alacranes

Mientras las aves soeces practican La eutanasia al día.

Bartolomé Nieto Munuera (2014) Noches de Quart Hadasht. Huerga \& fierro/ Colección el Diván, Madrid: p-23

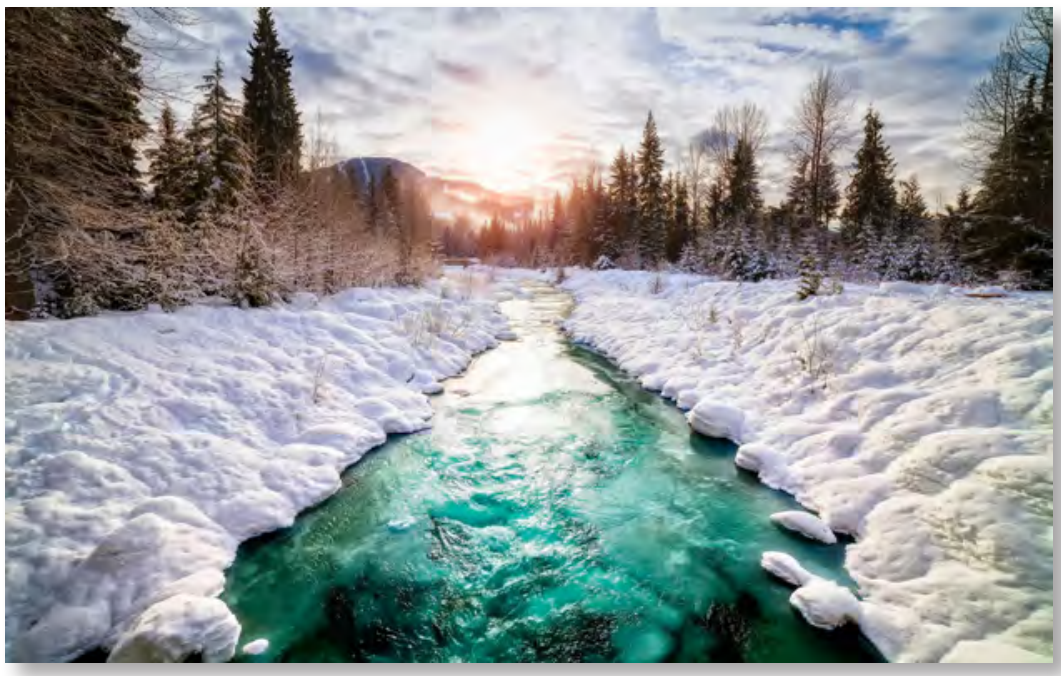

